\title{
Disparities in Motor Competence between Roma and Non-Roma Children in Croatia and Relations of Motor Competence, School Success and Social Economic Status
}

\author{
Ivan Serbetar ${ }^{1, *}$, Jan Morten Loftesnes ${ }^{2}$, Iva Prprovic ${ }^{1,3}$ \\ ${ }^{1}$ Faculty of Teacher Education, University of Zagreb, Croatia \\ ${ }^{2}$ Western Norway University of Applied Sciences, Norway \\ ${ }^{3}$ Sfera - Roma Family Center, Croatia
}

Copyright $(2019$ by authors, all rights reserved. Authors agree that this article remains permanently open access under the terms of the Creative Commons Attribution License 4.0 International License

\begin{abstract}
The purpose of this study was to investigate possible differences in the development of motor skills between native and Roma children in Northern Croatia, but also to establish relations of motor skills, school success and socioeconomic status. The sample of 114 children (57 Roma) of both gender (55 boys) were assessed by $M A B C-2$. Social economic status was represented by the mother highest level of education, and grade point average represented academic success. Regarding motor performance 9 children fall in the categories of "motor impairment" or "risk for impairment", 7 of them were Roma minority. MANOVA (gender) $x$ (ethnicity) was applied on manual dexterity, aiming and catching and balance and total standard score and both effects were significant $(\mathrm{p}=.000)$. Further univariate ANOVA's showed that the girls were better in manual dexterity $(\mathrm{p}=.000)$ and the boys in aiming and catching $(\mathrm{p}=.000)$. Non-Roma children performed better in manual dexterity $(\mathrm{p}=.000)$, balance $(\mathrm{p}=.000)$; and total test score $(\mathrm{p}=.000)$. Manual dexterity and ethnicity significantly $(\mathrm{p}=.000)$ predicted school success. Motor competence in Roma children was less developed than in native children. Poverty, parental-social but also environmental factors, significantly influence children's motor development.
\end{abstract}

Keywords Young School-age Children, Motor Competence, MABC-2, Ethnic Differences, Gender Differences, School Success

\section{Introduction}

Positive and successful movement experience is critically important for every child's life. Children learn by exploring their environment through movement [1]. Regular participation in movement and play activities may also lead to proficiency in motor skills, which in turn may affect future involvement in sports or physical activities and potentially preserve healthy body weight. There is also evidence that movement and physical activity may promote social success of the child and enhance academic achievement [2-4]. School age children, who evidence automaticity in motor skills, may have greater processing capacity available to learn more complex concepts, including symbolic representations of letters and numbers [5]. Namely, it seems that physical exercise has positive influence on executive functions [6] i.e. cognitive processes necessary for goal-directed cognition and behavior which develop across childhood and adolescence [7].

Proficiency levels of one's motor abilities and motor skills constitute motor competence [8], i.e. mastery of physical skills and movement patterns that enable enjoyable participation in physical activities [9]. White [10], suggested that competence is gained through interaction with environment, through playful and exploratory activities that "show direction, selectivity, and persistence in interacting with the environment" (p. 113).

However, indications occur pointing to interculturally different development of the motor competence, assuming traditional roles for boys and girls, which is implemented in child-rearing practices from early age. Gender differences in behavior may partly arise from differences in toys with which boys and girls tipically play, and parents socialize gender-typed behavior by selecting different toys and activities for boys or girls which may leads to different pattern in children's behavior [11]. Usually, the boys are found to be generally more motor skilled than the girls $[12$, 13].

Except gender differences, other culture related differences may be observed. Quah [15] proposed that parents from different ethnic backgrounds, and different levels of formal education, differ significantly in their 
parenting styles. Booth et al. [16] found relationships between object control proficiency and socioeconomic status, but also that gender and ethnic differences can influence proficiency in object control skills. Similarly, Pate et al [17] quoted several studies, where the associations among race/ethnicity, gender, socioeconomic status, and health outcomes were well established, they also pointed out that race/ethnicity and socioeconomic status may modify fitness performance.

The Roma children have traditionally been disadvantaged in many cultures $[18,19]$. Poverty and common social exclusion of that ethnic group largely determine child's academic success, while school deprivation and residential segregation may also cause underdevelopment of motor skills. Tsimaras et al. [20] reported that Greek-Roma children (7-10 yrs) performed significantly poorer in locomotion skills, handling skills and general motor ability. Equivalently, Zsidegh et al. [21] found that Hungarian-Roma boys (7-14 yrs) were significantly inferior in running, while Semoglou et al. [18] found that Greek-Roma preschool children significantly underachieved in visual motor integration, but not in the gross motor skills.

\section{Objectives}

Since the interrelations of ethnicity and motor competence in children were not investigated in Croatia, the aim of the present study was to evaluate possible differences in motor competence among Roma and native children in Croatia and to determine whether motor skills, along with the ethnicity and SES influence school success.

\section{Materials and Methods}

\subsection{Sample}

One third of all Croatian Roma population live in the Medjimurje County in the Northern Croatia, while all the other regional Roma communities are incomparably smaller. The sample of 114 children was drawn from two primary schools with the largest concentration of Roma children in the country. Children were equally distributed between Roma ( $\mathrm{n}=57)$ and non-Roma ethnicity $(\mathrm{n}=57), 55$ of them were boys and 59 girls. Age range of the children was 7 yrs and 9 months up to 10 yrs and 8 months, with a mean age of 8.27 yrs $( \pm .77)$. After informal meeting with the children, teachers and principals, they all expressed their agreement with the involvement in the study, and signed consents were obtained from the parents while children gave their oral assent. At the time of the assessment all the children were healthy and without known neurological or other dysfunctions.

\subsection{Measures}

We used the second edition of the Movement Assessment Battery for Children age band 2 (MABC-2) [22], which is a norm-referenced test comprising three age bands (3-6 years; $7-10$ years; and $11-16$ years) and consisting of eight motor items in each age band. MABC-2 is widely accepted tool in clinical and research community which assess three motor performance areas - manual dexterity (3 items), aiming and catching (2 items) and balance (3 items). The manual dexterity tasks include placing pegs into a board, threading lace, and drawing a line on a provided template. Aiming and catching tasks demands to throw a tennis ball to a wall and caught it with the hands with one bounce off/on the floor (7- and 8-year old) or directly without a bounce (9-and 10-year old). In the aiming task the child is requested to throw a beanbag onto a mat which is lying horizontally on the floor, 1.8 meters away. Balance tasks include one-leg stand on a balance board, heel-to-toe walking on a straight line and performing five successive hoops from one mat to another.

Except aiming and catching, all the tasks contains two trials and the best of two are rated. Aproximatelly 20 minutes were needed to assess one child. Provided norms allows standard scores for each item, component standard scores and total standard score. Since authors stated that the main purpose of the MABC-2 is identification of mild-to-moderate movement difficulties (i.e. Developmental Coordination Disorder; $D C D$ ) the test also allows to classify the subjects as normal developing, in the risk for impairment, and motor impaired.

Social economic status (SES) is ussualy determined by selecting the parental levels of education and/or income category. We adopted Entwisle and Astone [23] (p. 1526) stand of maternal education as a "human capital" in the home and used the mother highest level of education as an index of SES. The data were coded numericaly and the highest obtained level of the variable was used to represent socioeconomic status of the child. Four categories of data are formed: 1) not completed compulsory school $(\mathrm{n}=33), 2)$ completed compulsory school $(\mathrm{n}=29), 3)$ completed high school $(n=46), 4)$ college education $(n=6)$.

Academic school success was represented by grade point average (GPA) i.e. as cumulative average of all the grades in academic subjects and contained five levels.

\section{Results}

According to the percentile norms, stated in the manuals of the MABC-2, 4 children (3.5\%) fall in the category of motor impairment while another 5 children (4.4\%) fall in the risk for impairment, of those 9 altogether, 7 were Roma minority. Component standard scores are shown in Table 1. 
Table 1. Mean values of MABC-2 component standard scores and total standard score

\begin{tabular}{|c|c|c|c|c|c|c|c|c|c|}
\hline & \multicolumn{3}{|c|}{$\mathrm{MD}$} & \multicolumn{2}{|c|}{$\mathrm{AC}$} & \multicolumn{2}{|c|}{$\mathrm{B}$} & \multicolumn{2}{|c|}{ TSS } \\
\hline & $\mathrm{N}$ & Mean & SD & Mean & SD & Mean & SD & Mean & SD \\
\hline Girls Roma & 31 & 10.00 & 2.88 & 9.45 & 3.43 & 9.23 & 3.61 & 9.48 & 3.21 \\
\hline Boys Roma & 26 & 7.85 & 2.65 & 10.54 & 3.20 & 9.73 & 3.46 & 8.69 & 2.38 \\
\hline Girls Non-Roma & 28 & 12.25 & 2.35 & 8.96 & 3.46 & 12.18 & 3.16 & 11.5 & 2.73 \\
\hline Boys Non-Roma & 29 & 10.48 & 2.73 & 12.17 & 2.54 & 11.69 & 2.51 & 11.86 & 2.45 \\
\hline Total & 114 & 10.18 & 3.04 & 10.27 & 3.38 & 10.69 & 3.42 & 10.4 & 3.00 \\
\hline
\end{tabular}

MD - manual dexterity; AC - aiming and catching; B - balance; TSS - Total standard score;

To test the influence of the independent variables of ethnicity and gender on motor skills, a MANOVA 2 (gender) x 2 (ethnicity) was applied with three component standard scores (manual dexterity, aiming and catching, balance) and total standard score as dependent variables. Usual assumptions of MANOVA, like multivariate normality, Mahalanobis distances and multicolinearity were checked, and no violations were found. Box's test of equality of covariance matrices, as well as Levene's test, were not significant.

MANOVA revealed significant effects of gender (Wilks' Lambda $\left.=.729, \mathrm{~F}(4,107)=9.956, \mathrm{p}=.000, \eta_{\mathrm{p}}^{2}=.271\right)$ and ethnicity (Wilks' Lambda $=.754, \mathrm{~F}(4,107)=8.729, \mathrm{p}=.000$, $\eta_{\mathrm{p}}^{2}=.246$ ). Subsequent ANOVA analysis showed that the girls were better in manual dexterity $\mathrm{F}(1,110)=15.350$, $\left.\mathrm{p}=.000, \eta_{\mathrm{p}}^{2}=.122\right)$ while the boys outperformed girls in aiming and catching $\left.\mathrm{F}(1,110)=12.935, \mathrm{p}=.000, \eta_{\mathrm{p}}^{2}=.105\right)$.

Also, non-Roma children performed better then Roma children in manual dexterity $(\mathrm{F}(1,110)=23.840, \mathrm{p}=.000$, $\left.\eta_{\mathrm{p}}^{2}=.178\right)$, balance $\left(\mathrm{F}(1,110)=16.565, \mathrm{p}=.000, \eta_{\mathrm{p}}^{2}=.131\right)$; and total test score $\left(\mathrm{F}(1,110)=25.610, \mathrm{p}=.000, \eta_{\mathrm{p}}^{2}=.189\right)$.

Further posthoc analysis using Bonferroni criteria showed that regarding manual dexterity native girls outperformed both, Roma boys $(\mathrm{p}=.000)$ and Roma girls $(\mathrm{p}=.01)$, while Roma girls were still significantly better then Roma boys $(p=.018)$. Other differences were not significant.

Posthoc for aiming and catching revealed that native boys scored significantly better than both, Roma girls $(\mathrm{p}=.008)$ and native girls $(\mathrm{p}=.001)$. Roma boys didn't differ significantly from neither of groups.

In balance, Roma girls didn't differ from Roma boys. However, native girls were better than Roma girls $(p=.004)$ and Roma boys $(\mathrm{p}=.034)$, while native boys were better than Roma girls $(\mathrm{p}=.022)$. We also checked whether the academic school success is influenced by the level of motor competence or by the ethnicity or socioeconomic status (SES). Ordinal regression analysis was performed on the output (dependent) variable of the $G P A$, which was ordered in 5 categories. In the first run we included $M A B C-2$ total standard score, SES, gender and ethnicity as predictors. The analysis revealed that $M A B C-2$ total standard score and the ethnicity significantly predicted GPA but, gender, and surprisingly, SES, did not. Although $M A B C-2$ total standard score was significant, we wanted to examine influence of manual dexterity on the model by subtracting it from $M A B C-2$ total standard score. After removal of manual dexterity, total standard score was no more significant. In final run, we included only $M D$ standard score and ethnicity in the analysis. The predictors significantly accounted for moderate proportion of variance in outcome - Nagelkerke $R^{2}=.341$; likelihood ratio $\chi^{2}(2)=43.695, \mathrm{p}<.001$.

The model showed systematic effect in GPA related to the manual dexterity and to the ethnic group. Both significantly predicted $G P A(\mathrm{p}=.000)$. Regarding to the manual dexterity the coefficient was .260 ( $\mathrm{SE}=.068$, $\mathrm{p}<.001$ ), by taking the exponent we get odds ratio (OR) of 1.3 , which indicates that odds of having higher GPA increases by 1.3 for each unit increase in manual dexterity. Also, the significant positive coefficient of ethnicity 1.646 $(\mathrm{SE}=.414, \mathrm{p}<.001)$ indicated, in OR terms, that non-Roma children are 5.19 times more likely to have higher grade than Roma children.

\section{Discussion}

The study primarily attempted to identify differences between Roma and non-Roma children in motor competence and also to establish relationships between motor skills, ethnicity, socioeconomic status and school success.

We found that 7 (12.3\%) out of 57 Roma children were classified in the categories of motor impairment and risk for impairment. In non-Roma sub-sample only 2 children $(3.5 \%)$ were in the risk for impairment category.

Prevalence of motor impairment (DCD) varies across studies/countries, i.e. according to [24] there is $6 \%$ in USA, $2 \%$ UK [25], 5.4\% in Greece [26] and $4.5 \%$ in Norway [27].

Gender differences were not surprising, but their marked conjunction with ethnicity is what is noticeable the most. Native children did not differentiate in manual dexterity but they outperformed Roma boys and girls significantly. Non-Roma boys scored significantly better in aiming and catching than both girl groups. In balance, again, native children scored better than Roma minority. Crespo et al. [28] (2013) allege that in nearly all of the reviewed pediatric studies, boys were more active than girls. For the specific age group of 6-11 year-olds, which is in compliance with the current study sample, they state that 
boys were engaged in physical activity 20 more daily minutes than did the girls. The authors explained that girls may have lower intentions and expectations to exercise, lower perceived behavioral control, lower self-confidence to exercise, less social support and less enjoyment of PA and sports participation than boys [28].

Weaker performance of Roma children in the manual dexterity was expected. They live mostly in a powerty of deprived surroundings of small crowded houses with lack of the furniture and sometimes even without electricity or running water. Families commonly have many children sharing just one toy, while the households missing small house utensils like the scissors, pencils or paper and other play material which dramaticaly reduce opportunities for practice and development of fine motor skills. Relations of fine motor skills and school success are well established in many studies. It is known that, in preschool age, fine motor skills predict later reading and math achievement [29]. We found that manual dexterity significantly predicted overall school success measured as grade point average. We also found that beeing of Roma minority substantially lowered children possibilities for academic achievement. Although overall reasons may be complex and multifactorial, we propose primarily lack of reinforcement in learning and practice by parents and siblings as the main reason. It is known that in Roma population older children spend large amount of daily time taking care for their numerous younger siblings. Parents, on the other hand, doesnt find any usefullnes of encouragement of the children neither in motor activities nor in learning and studying in general. The rate of school absenteeism, grade retention and behavioral problems is high. In Roma population in the present study, numerous children were born to teen mother and in their families the official language (native) is not spoken, they experienced pour pre- and postnatal care, and almost all live in poverty. They also did not participate in kindergarten care and education, and therefore missed the early opportunities for organized participation in structured movement and play activities. Fantuzzo et al. [30] indicated that children with early care and education experience scored significantly higher on motor skills than children who did not participate in early childhood programs.

It is known that gender and ethnicity can influence proficiency in object control skills, which provide children with the tools to be physically active and which is a major societal priority [31]. This is especially important because the middle childhood is a period of vulnerability during which children with lower actual motor skill proficiency will likely become less physically active because of the lower perceived motor competence [32].

Herbst and Huysamen [33] suggested that environmentally disadvantaged children are superior in activities requiring gross motor skills, whereas their peers from more advantaged communities outperform them in fine motor skills. Accordingly, it is reasonable to expect that children from poorer socioeconomic environment should have higher level of gross motor skills due to more time spent in outdoor activities. However, that was not the case in the present study. Moreover, not only was Roma children's performance in ball skills (gross-motor) lower, but they also showed significantly lower level of balance, which could also be considered a gross motor skill because of the involvement of large muscles of the body in maintaining the body equilibrium. It is questionable whether Roma children spend more time outdoors, but even if they do, it obviously does not automatically guarantee higher level of motor skills. That is in accordance with [34], who observed that children from the lowest socioeconomic families were engaged in less physical activity than children from the highest socioeconomic families, while among girls, those with the lowest socioeconomic status spent the greatest amount of time watching TV $(p=0.0001)$.

Goodway and Branta [35] found that children living in high-risk environments are at risk of developmental delays but also school failure. Except for lack of possibilities for motor skills development, in such a milieu, children are exposed to other risk factors that contribute to their overall reduced development, like exposure to drugs, alcohol, or crime. Equipped playgrounds are mostly not available to Roma children to the same extent as they are to native children. For optimal perceptual-motor development, stimulating home environment should be accompanied by enjoyable play and exercise facilities and surroundings, which should be accessible, well structured, and should increase children's opportunity to be physically active and to develop motor skills.

\section{Conclusions}

Our study showed that motor competence is less developed among Roma children than among the native children. Seven percent of Roma children were classified as below normal motor development. Roma children were less successful in gross-motor skills and considerably less successful in fine motor skills than non-Roma children. The latter negatively predicted their school success leaving them behind non-Roma children.

It is reasonable to assume that poverty, parental-social but also environmental factors, significantly influenced children's motor development, as well as their academic achievement and social engagement.

In a broader context of the current immigration processes in Europe, once homogenous communities and neighborhoods may progressively become ethnically and racially diverse. In such complex societies it should be ensured that all children receive optimal social and environmental opportunities, which will increase children's chance for adequate and useful motor experience and thus enhance their development. 


\section{REFERENCES}

[1] J.E. Clark. On the problem of motor skill development, Journal of Physical Education Recreation and Dance, 78(5), pp 39-44 2007.

[2] C.L. Davis, P.D. Tomporowski, J.E. McDowell, B.P. Austin, P.H. Miller, N.E. Yanasak, J.D. Allison, J.A. Naglieri. Exercise improves executive function and achievement and alters brain activation in overweight children: a randomized, controlled trial, Health psychology, 30(1), 91 - 82011.

[3] S.A. Carlson, J.E. Fulton, S.M. Lee, L.M. Maynard, D.R. Brown, H.R. Kohl III, W.H. Dietz. Physical education and academic achievement in elementary school: Data from the early childhood longitudinal study, American Journal of Public Health, 98(4), 721-727 doi: 102105/AJPH20071171762008.

[4] J.E. Donnelly, J.L. Greene, C.A. Gibson, B.K. Smith, R.A. Washburn, D.K. Sullivan, S.L. Williams. Physical activity across the curriculum (PAAC): A randomized controlled trial to promote physical activity and diminish overweight and obesity in elementary children, Preventive Medicine, 49(4), 336-341 2009.

[5] C. Cameron, L.L. Brock, W.M. Murrah, L. Bell, S. Worzalla, D. Grissmer, and F.J. Morrison. Fine motor skills and executive function both contribute to kindergarten achievement, Child Development, 83(4):1229-44 2012

[6] C.H. Hillman, K.I. Erickson, A.F. Kramer. Be smart, exercise your heart: exercise effects on brain and cognition, Nature Reviews Neuroscience, 9(1), 58-65 doi: 101038/nrn2298 2008.

[7] J.R. Best. Effects of physical activity on children's executive function: Contributions of experimental research on aerobic exercise, Developmental Review, 30(4), 331-351 2010.

[8] S.W. Logan, E. Kipling Webster, N. Getchell, K.A. Pfeiffer, L.E. Robinson. Relationship between Fundamental Motor Skill Competence and Physical Activity during Childhood and Adolescence: Systematic Review, Kinesiology Review, 4, 416-426 2015.

[9] D.M. Castelli and J.A. Valley. Chapter 3: The Relationship of Physical Fitness and Motor Competence to Physical Activity, Journal of Teaching in Physical Education, 26, 358-374 2007.

[10] W.R. White. Motivation Reconsidered: The Concept of Competence, In Glenn $\mathrm{T}$ Morris (ed) Dimensions of Psychology, 81-118, MSS Educational Pub Co, New York 1971.

[11] Y.M. Caldera, A.C. Huston, M. O'Brien. Social interactions and play patterns of parents and toddlers with feminine, masculine, and neutral toys, Child Development, 60:70-76 1989.

[12] L.M. Barnett, E. Van Beurden, P.J. Morgan, O. Lyndon, and J.R. Beard. Gender differences in motor skill proficiency from childhood to adolescence, Research Quarterly for Exercise and Sport, 81, 162 - 1702010.

[13] J.D. Goodway, L.E. Robinson \& H. Crowe. Gender Differences in Fundamental Motor Skill Development in Disadvantaged Preschoolers from Two Geographical Regions, Research Quarterly for Exercise and Sport, 81:1, $17-242010$

[14] M.E.G. Armstrong, E.V. Lambert, and M.I. Lambert Physical fitness of South African primary school children, 6 to 13 years of age: Discovery Vitality Health of the Nation Study, Perceptual and Motor Skills, 113 (3), 999 10162011.

[15] S.R. Quah. Ethnicity and parenting styles among Singapore families, Marriage and Family Review, 35, 63-83 2004.

[16] M.L. Booth, T. Okely, L. Mclellan, P. Phongsavan, P. Macaskill, J. Patterson, J. Wright, and B. Holland. Mastery of fundamental motor skills among New South Wales school students: prevalence and sociodemographic distribution, Journal of Science and Medicine in Sport, 2 (2), 93 - 1051999

[17] R. Pate, M. Oria, and L. Pillsbury. Fitness measures and health outcomes in youth, National Academies Press, Washington, DC 2012.

[18] K. Semoglou, A. Alevriadou, and A. Tsapakidou. Gross and fine motor skills: The case of Roma, European Psychomotricity Journal, vol 1, pp 17-22 2008.

[19] L. Walls. The effects of SUMNAL on the developmental skills of Roma children, Utrecht: Universiteit Utrecht 2013.

[20] V. Tsimaras, D. Arzoglou, E. Fotiadou, D. Kokaridas, M. Kotzamanidou, N. Angelopoulou, E. Bassa. Gross motor ability of native Greek, Roma, and Roma immigrant school-age children in Greece, Perceptual and Motor Skills, 112(1):279-88 2011

[21] P. Zsidegh, A. Photiou, Z. Mészáros, A. Prókai, I. Vajda, Á. Sziva, J. Mészáros. Body Mass Index, Relative Body Fat and Physical Performance of Hungarian Roma Boys, Kinesiology, Vol 39 No1 2007.

[22] S.E. Henderson, D.A. Sugden, A.L. Barnett. Movement Assessment Battery for Children-2, London: Harcourt Assessment 2007.

[23] D.R. Entwisle and N.M. Astone. Some Practical Guidelines for Measuring Youth's Race/Ethnicity and Socioeconomic Status, Child Development, Vol 65, No 6 pp 1521-1540 1994.

[24] American Psychiatric Association. DSM-IV-TR. Diagnostic and statistical manual of mental disorders (4th ed., text revision), Washington, DC: American Psychiatric Association. 2000.

[25] R. Lingam, L. Hunt, J. Golding, M. Jongmans, A. Emond. Prevalence of developmental coordination disorder using the DSM-IV at 7 years of age: A UK population based study, Pediatrics, 123(4), e693-700 2009.

[26] P. Giagazoglou, N. Kabitsis, D. Kokridas, C. Zaragas, E. Katartzi, and C. Kabitsis. The movement assessment battery in Greek preschoolers: The impact of age, gender, birth order, and physical activity on motor outcome, Research in Developmental Disabilities, 32(6), 2577-2582 
2011.

[27] I. Holm, A.T. Tveter, V.S. Aulie, B. Stuge. High intra- and inter-rater chance variation of the movement assessment battery for children 2, ageband 2, Research in developmental disabilities, 34(2) 795-800 2013.

[28] N.C. Crespo, K. Corder, S. Marshall, G.J. Norman, K. Patrick, J.F. Sallis and J.P. Elder. An Examination of Multilevel Factors That May Explain Gender Differences in Children's Physical Activity, Journal of Physical Activity and Health, 10, 982-992 2013.

[29] D. Grissmer, K.J. Grimm, S.M. Aiyer, W.M. Murrah, and J.S. Steele. Fine motor skills and early comprehension of the world: Two new school readiness indicators, Developmental Psychology, 46, 1008-1017 2010.

[30] J. Fantuzzo, H.L. Rouse, P. McDermott, S. Childs, and A. Weiss. Early Childhood Experiences and Kindergarten Success: A Population-Based Study of a Large Urban Setting, School Psychology Review 34 (4), 571-588 2005.

[31] S.A. Butterfield, R.M. Angell, C.A. Mason. Age and Sex Differences in Object Control Skills by Children Ages 5 to 14, Perceptual and Motor Skills, 114(1):261-74 2012.

[32] D.F. Stodden, J.D. Goodway, S.J. Langendorfer, M.A. Roberton, M.E. Rudisill, C. Garcia, and L.E. Garcia. A. Developmental Perspective on the Role of Motor Skill Competence in Physical Activity: An Emergent Relationship, Quest, 60, 290-306 2008.

[33] Herbst I. and Huysamen G.K. The construction and validation of developmental scales for environmentally disadvantage preschool children, South African Journal of Psychology, 30(3), 19-25 2000.

[34] M.L. De Frenne, F.J. Zaragozano, J.M. Garagorri Otero, A.L. Moreno, B.M. Sanchez. Physical activity and leisure time in children I: Relation to socioeconomic status, Anales Españoles de Pediatría, 46(2):119-25 1997.

[35] J.D. Goodway and C. Branta. Influence of a motor skill intervention on fundamental motor skill development of disadvantaged preschool children, Research Quarterly for Exercise and Sport, 74, 36-46 2010. 